\title{
O que mudou na grande Salvador? Um breve estudo sobre a evolução dos aspectos sócio-ocupacionais na Região Metropolitana de Salvador entre 2003 e 2010
}

Ualace Roberto de Jesus Oliveira ${ }^{1}$

1 Mestre em Economia pela Universidade Federal da Bahia, Brasil. E-mail: ualacejesus@bol.com.br

RESUMO: Até o primeiro triênio dos anos 2000 parcela importante da força de trabalho da Região Metropolitana de Salvador (RMS) encontrava-se desempregada, enquanto um número significativo de famílias vivia em condições precárias de vida. Vale ressaltar que essas e outras questões sociais adversas contribuíam para projetar Salvador e Região Metropolitana no cenário nacional como umas das cidades mais desiguais do país. Porém, passou a vigorar no Brasil a partir de 2004 um importante processo de crescimento econômico, com efeitos reais sobre os aspectos sócio-ocupacionais da Grande Salvador, fato que corroborou para atenuar o quadro social até então vigente. Diante do que foi exposto, este trabalho tem como objetivo observar a melhoria ocorrida nos aspectos sócio-ocupacionais em Salvador e Região Metropolitana entre os anos 2003-2010. Para tanto, é feita uma análise a partir do banco de dados da Pesquisa de Emprego e Desemprego (PED), para os anos situados entre 2003 a 2010. A metodologia utilizada consiste numa análise descritiva, com auxílio de gráficos e tabelas dos dados encontrados. Os resultados revelam que embora tenha havido melhorias consideráveis em muitos aspectos sociais e ocupacionais na RMS, ainda continua havendo na referida região graves problemas sociais.

Palavras-chave: Mercado de trabalho. Crise. Renda.

What has changed in the great salvador? A brief study on the evolution of socio-occupational aspects in the metropolitan region of salvador between 2003 and 2010

ABSTRACT: Until the first three years of the 2000s, a significant portion of the Salvador Metropolitan Region's labor force was unemployed, while a significant number of families lived in precarious conditions. It is noteworthy that these and other adverse social issues contributed to design Salvador and the Metropolitan Region in the national scenario as one of the most unequal cities in the country. However, an important process of economic growth, with real effects on the socio-occupational aspects of the Great Savior, began to take effect in Brazil in 2004, a fact that corroborated the already weak social profile. In view of the above, this study aims to observe the improvement in socio-occupational aspects in Salvador and Metropolitan Region between 2003-2010. To do so, an analysis is made from the database of the Survey of Employment and Unemployment (PED), for the years between 2003 to 2010. The methodology used is a descriptive analysis, using graphs and tables of the data found. The results show that although there have been considerable improvements in many social and occupational aspects of MSY, there are still serious social problems in the region.

Keywords: Job market. Crisis. Income.

\section{INTRODUÇÃO}

Em um mundo cada vez mais integrado pela globalização, nenhum lugar está imune aos efeitos produzido por esse fenômeno, principalmente regiões que apresentam as 
características que a Região Metropolitana de Salvador possui. Marcada por profundas desigualdades sociais, a Grande Salvador convive com problemas sociais históricos, problemas que foram, inclusive, agravados pelo quadro de instabilidade econômica vivenciada pelo Brasil nos anos $1990^{1}$. A intensificação das contradições sociais na referida região nesse processo contribuiu para agravar uma histórica dicotomia existente na capital baiana, que é: "Salvador com pouquíssimos ricos e com muitos pobres e miseráveis" ${ }^{2}$. Assim, os termos "cidade alta" e "cidade baixa", usados para delimitar geograficamente a cidade do Salvador, passaram a ter também uma conotação de cunho social, uma vez que passaram a evidenciar a perversa estrutura social que há na referida cidade, onde parcela majoritária da sua população, que é paupérrima, sobrevive na periferia, enquanto uma diminuta parcela abastada reside nas áreas mais nobres.

Mas vale ressaltar que os avanços sociais ocorridos na economia brasileira nos últimos anos, principalmente a partir de 2004, impactaram positivamente as questões de cunho social e ocupacional das regiões metropolitanas do país, dentre as quais a RMS está inserida. Dito isso, os dados de pesquisas referentes à ocupação da força de trabalho da População Economicamente Ativa

\footnotetext{
${ }^{1}$ Além das medidas proposta pelo FMI por meio do consenso de Washington, que pregava a redução da participação do Estado na economia (Estado mínimo), medidas que agravaram os problemas sociais do Brasil, o Brasil se deparou com crises internacionais graves, tais como a crise do México em 1998, a crise dos tigres asiáticos 1997 e a crise da Rússia, e promove um radical processo de reestruturação produtiva.

2 Alusão ao livro intitulado "Bahia de todos os pobres", clássico da literatura regional nordestina que aborda o fenômeno da pobreza aguda existente em Salvador e Região Metropolitana de sua formação até 1980.
}

de Salvador e Região Metropolitana, demonstram que ocorreu um importante processo de expansão do emprego formal entre 2003 e 2010, embora a maior parte das oportunidades criadas no mercado de trabalho tenha ocorrido em atividades que exige apenas baixa qualificação técnica da força de trabalho.

Diante do que foi exposto o problema da pesquisa consiste em saber: os avanços sociais vivenciados pela RMS entre os anos 2003 e 2010 provocou uma radical transformação em seus aspectos sociais e ocupacionais? Para tanto parte da hipótese que tal fato não se verifica.

O objetivo deste trabalho é observar a evolução ocorrida nos aspectos sócio ocupacionais na RMS entre os anos 2003-2010.

$O$ presente trabalho se justifica com intuito de entender as principais mudanças verificadas nos aspectos sociais na Grande Salvador de 2003 a 2010.

Com a finalidade de alcançar os objetivos do trabalho, realizou-se uma análise a partir de bancos dados da Pesquisa de Emprego e Desemprego (PED) disponibilizados pela SEI/DIEESE para os de 2003 e 2010.

\section{A RMS A PARTIR DE 1950}

Para entender as questões de cunho sócio-ocupacional da Grande Salvador de hoje é necessário analisar, ainda que sucintamente, os aspectos sociais e econômicos que remota seu passado.

Dito isso, conforme afirma Bacelar (1994), a partir da década de 1950 a Região Metropolitana de Salvador vivencia uma radical transformação na sua estrutura produtiva. É salutar ressaltar que as mudanças ocorridas a partir de então na Bahia e no recôncavo, com efeitos na economia da 
RMS, resultou da implementação das atividades de exploração do petróleo por meio da Petrobrás. De acordo com Oliveira (2003) a massa de investimentos da Petrobrás não tem paralelo na história econômica do Bahia, visto que entre 1955 e 1959, o total desses investimentos correspondeu de $1 \%$ até $7,4 \%$ da renda total e de $8,1 \%$ a $66,9 \%$ da renda interna industrial do Estado da Bahia. A massa de salários pagos pela Petrobrás na economia baiana crescera à razão anual de $18 \%$ reais no nesse período. Do lado dos inputs demandados pela Petrobrás, os linkages que se estabelecem dão lugar a uma forte dinâmica na construção civil, pois conforme Carvalho e Souza (1980, p.77) esse fato acabou criando:

13.000 empregos diretos, pagando altos salários, demandando por construção civil e por obras de infraestrutura. Ademais a empresa influiu fortemente para o aumento do mercado microrregional de Salvador e para expansão dos serviços, principalmente. Surgiram algumas indústrias complementares à atividade da empresa a partir de então, o que implicou expansão dos ramos químico e metalúrgico, com mudança na sua própria composição interna. A expansão da construção civil, incentivada pela implantação da empresa e pela urbanização de Salvador, por seu turno, estimulou o surgimento de várias empresas no ramo de minerais metálicos (...). As indústrias dinâmicas que comandaram a criação de empregos nesse período, a despeito do seu caráter intensivo.

Ademais, a Petrobrás e o complexo petroquímico de Camaçari, corroboraram para criar de forma direta e indireta um restrito mercado de trabalho em Salvador para profissionais de alta qualificação técnica e cien- tífica (GUIMARÃES, 1987). Porém, como assinala Oliveira (2003), os impactos sobre a criação de empregos diretos foi de pequena expressão, pois:

Em 1960 tão-somente 2.200 pessoas achavam-se ocupadas como trabalhadores na extração e exploração de petróleo e gás natural, número que em 1970 sub 2.572. Entretanto, a criação de empregos não-operários foi bem maior: $7.595 \mathrm{em}$ 1970, compreendendo-se nesses totais pessoal técnico (engenheiro, geólogos, químicos, gerentes, supervisores) e pessoal de escritório. A criação de empregos indiretos foi expressivamente maior; a relação entre emprego no secundário e emprego no terciário, de 2,6\% em Salvador, é uma aproximação válida para a influência da Petrobrás sobre empregos indiretos (OLIVEIRA, 2003, p.58).

A complexa relação técnico-econômica que preside a industrialização na capital baiana pôs em jogo uma rotatividade da mão de obra operária que é um dos principais aspectos da constituição de um expressivo "exército industrial de reserva" ${ }^{3 "}$. De acordo com Carvalho e Barreto (2004) essas transformações incidiram sobre um mercado de trabalho marcado por uma superoferta de mão-de-obra de baixa qualificação, reforçada pela atração de intensos fluxos migratórios para Salvador e por uma oferta restrita de postos de qualidade, com

\footnotetext{
${ }^{3}$ Exército industrial de reserva é um conceito marxista que corresponde à força de trabalho que excede as necessidades da produção. Para o bom funcionamento do sistema de produção capitalista e garantir o processo de acumulação é necessário que parte da população ativa esteja permanentemente desempregada. Esse contingente de desempregados atua como um inibidor das reivindicações dos trabalhadores e contribui para o rebaixamento dos salário
} 
salários mais elevados e possibilidades de ascensão profissional.

Sob o prisma da estrutura social, as atividades da Petrobrás instauraram a existência de novos grupos sociais bem demarcados em relação à estrutura social preexistente em Salvador e Recôncavo. Um grupo social de operários, gota d'água no oceano do desemprego; a rigor, um novo grupo operário isolado contraditoriamente pela novidade de sua existência na estrutura social do Recôncavo e de Salvador, ao lado dos outros "irmãos de classe" empregados ainda em industriais tecnicamente atrasadas. E outro grupo social, dos funcionários não operários, heterogêneo do ponto de vista de suas ocupações e dos seus níveis de salário, igualmente isolado: os de mais altos salários eram comparados, igualando-se pelas rendas, aos grupos oligárquicos locais. Esse fator pesou enormemente no efeito social e político que as atividades modernas da Petrobrás tiveram sobre as ancilares estruturas da Bahia (OLIVEIRA, 2003).

Segundo Santos (1994) foi com base nas diretrizes do II PND, na metade dos anos 1970, em plena urgência do "Brasil grande potência" do regime militar, que se assistiu a consolidação definitiva do complexo petroquímico de Camaçari (COPEC), que passou a funcionar a partir de 1978. "A implantação do COPEC representou uma operação complexa, com participação conjunta do Estado, de empresas privadas, internacionais e de empresas privadas nacionais" (SANTOS, 1994, p.2). Neste modelo, as multinacionais tiveram uma participação importante na incorporação de tecnologia e o Estado, tanto como principal investidor direto, através da Petrobrás e subsidiárias, como pela implementação e controle de algumas formas privilegiadas de incentivos financeiros e ficais:
A magnitude dos incentivos fiscais para o complexo petroquímico pode ser consta- do, de forma indireta, pelas informações baseadas na pesquisa feita pela SUDE- NE/BNB, em 1978, portanto, no primeiro ano de efetivo funcionando do complexo, na qual $48,5 \%$ do total dos investimentos fixos realizados pelas indústrias incenti- vadas no Nordeste estavam concentradas na RMS. Por outro lado, a indústria quí- mica, fundamentalmente representada pelos novos projetos petroquímicos, par- ticipou, neste mesmo ano, com cerca de $40 \%$ do volume das inversões (SANTOS, 1994, p.3)

De acordo com Carvalho, Ângela e Pereira (2004) dos anos 70 aos 80, os esforços desenvolvimentistas do governo federal para complementar a matriz industrial brasileira - com a produção de insumos básicos e bens intermediários - aproveitaram vantagens locacionais existentes para a implementação do Polo Petroquímico de Camaçari, que se converteu no foco dinâmico da economia regional, comandando a expansão e a diversificação da sua estrutura produtiva, e do Complexo do Cobre. Assim:

Esses e outros investimentos tiveram um impacto extraordinário sobre a velha capital baiana, ampliando, inclusive, suas articulações espaciais com os municípios vizinhos de Simões Filho, Candeias e Camaçari, que sediam as novas indústrias, e dando início à formação da Região Metropolitana de Salvador (RMS). Composta por 10 municípios bem distintos em termos de área, população e condições socioeconômicas, mas com uma integração e uma complementaridade que se superpõem à sua diferenciação, a RMS, tornou- 
se responsável por mais de $80 \%$ da indústria de transformação e mais da metade da produção e da riqueza estadual (CARVALHO; ÂNGELA; PEREIRA 2004, p.119).

Mas vale relatar que a década de 1980 foi particularmente difícil para a economia brasileira, visto que o país passou a vivenciar uma forte crise econômica provocada pelos efeitos da chamada "crise da divida externa"4 , esta que levou a economia brasileira a produzir baixas taxas de crescimento econômico associada a elevadas taxas de desemprego e inflação.

Contudo, a situação da RMS nesse processo foi diferente, visto que somente a partir de 1983 iniciou-se a queda em seu nível de emprego e do Produto Interno Bruto $(P I B)$. Isso porque, como foi dito, a segunda metade da década de 1970 caracteriza-se pelo intenso crescimento econômico liderado pela implantação do II Pólo petroquímico brasileiro, em Camaçari, fato que alterou sensivelmente a estrutura produtiva da Bahia. Assim:

A década de 80 iniciou-se, assim, sob o impacto dessas transformações. Por isso mesmo, quando a recessão era uma realidade no restante do país, a economia baiana ainda crescia, beneficiada pelos efeitos da maturação dos investimentos do pólo-petroquímico, perceptíveis não apenas no setor industrial, mas também no comércio e nos serviços, aí incluídos os

\footnotetext{
${ }^{4}$ Durante a década de 1970 o Brasil aproveitou a abundância de crédito para realizar um grande plano de investimento. A crença na continuidade das condições favoráveis e no aumento dos fluxos de comércio internacional deixou o país vulnerável. A elevação do serviço da dívida em decorrência do aumento da taxa de
juros e a dificuldade na obtenção de divisas devido a ço da dívida em decorrência do aumento da taxa de
juros e a dificuldade na obtenção de divisas devido a diminuição das exportações levou a uma séria crise de
liquidez. diminuição das exportações levou a uma séria crise de
liquidez.
}

de infraestrutura e os de intermediação financeira (CASTRO; BARRETO, 1998, p.43).

Após três anos de intensa recessão o país retomou, em 1984, o ritmo de crescimento econômico com sensível recuperação do nível de emprego, principalmente no Sudeste. Nesse ano, entretanto, a Bahia passou a enfrentar um processo de crise econômica; o índice de desemprego sobe contrariando o movimento que estava ocorrendo no resto do país. Porém, já em 1985, a atividade econômica baiana experimenta uma lenta recuperação que se estendeu até meados de 1986. Tal fato resultou, por um lado, da reconversão da produção industrial moderna para o mercado internacional e, por outro, do investimento público, que mantém no período os seus elevados índices. "Essas iniciativas minimizaram sem, contudo, eliminar os efeitos da crise na Bahia (CASTRO E BARRETO, 1998, P.44). Só na segunda metade de 1980 passaram a convergir as tendências locais e nacionais. Mesmo assim, na RMS, o crescimento do emprego se fez com maior lentidão, razão pela qual se ampliou a defasagem em relação às tendências nacionais. Nesse processo:

A estabilidade tomou conta do ano de 1987, sendo apenas rompida ao seu final com a retomada do crescimento, tanto local como nacional, numa tendência que se prolonga pelo ano de 1988. A partir daí, estabeleceu-se um novo período de instabilidade dos níveis nacionais do emprego, cujo impacto, todavia menos significativo na RMS, prevalecendo a tendência à estabilização. Vemos, assim, que os anos 80 findam consagrando a aproximação gradual entre as tendências locais do emprego, sem que, entretanto, Bahia ou 
Brasil apresentaram nem de longe a pujança do crescimento vivenciado nos anos 70 (CASTRO; BARRETO, 1998, p.45).

Nos anos 1990, conforme Carvalho e Barreto (2007) ocorreu um dos mais intensos processos de retração das oportunidades de trabalho na RMS. A reestruturação produtiva pela qual passou a economia brasileira reforçou os efeitos deletérios sobre os aspectos sócio-ocupacionais de Salvador e Região Metropolitana, na medida em que ocasionou redução expressiva dos postos de trabalho em todos os setores, além de corroborar para o aumento das ocupações precárias e elevar o desemprego:

Na região metropolitana, onde Salvador concentra $80 \%$ da população, os empregados representavam apenas $53,5 \%$ dos ocupados e a proporção daqueles com carteira assinada não ia além de 67,2\%. A precariedade ocupacional e a vulnerabilidade social se expressavam, igualmente, por meio do peso dos ocupados por conta própria $(23,2 \%)$ e empregados domésti$\cos (10,5 \%)$, de taxas de desemprego superiores às verificadas nas demais metrópoles nacionais, do nível de rendimento dos trabalhadores e da frequência de pobres na população (CARVALHO; BARRETO, 2007, p.4).

Por conta de tal fato, de acordo com Carvalho e Pereira (2008), a RMS apresentava no fim da década de 1990, um dos piores índices de desigualdade entre dez das mais importantes regiões metropolitanas do país. Ademais, o rendimento médio da população da RMS era bem inferior ao verificado nas capitais do Sudeste e Sul do país. Essa situação não se alterou nos primeiros anos do século XXI. Pelo contrário, os rendimen- tos médios e medianos mensais da população de Salvador voltaram a cair, entre o final dos anos 1990 e o início da década seguinte, quando atingiram, respectivamente, os níveis de $\mathrm{R} \$$ 798,5 e R\$ 401,00.

Em 1991, do total da população residente em Salvador, 59,58\% dos chefes do domicílio tinham rendimento até $3 \mathrm{SM}$ e $70,9 \%$, até 5 SM, enquanto apenas 3,88\% percebiam mais de 20 SM e 6,69\% encontravam-se sem rendimento. Ainda que, em 2000, os índices até 3 e até 5 SM tenham diminuído, respectivamente para 49,31\% e 61,68\%, mantendo-se índices próximos nas faixas imediatamente superiores, aumentos significativos ocorreram na faixa mais de $20 \mathrm{SM}$ e, sobretudo, na categoria sem rendimento, passando para $4,59 \%$ e $13,47 \%$, respectivamente (CARVALHO; ÂNGELA; PEREIRA, 2004, p. 10).

Tanto a evolução histórica como as transformações dos últimos anos contribuíram para a conformação de uma metrópole periférica e bastante desigual, com ilhas de afluência em um cenário de pobreza generalizada. Assim, a estrutura social da Região Metropolitana de Salvador passou a ser formada por uma pequena elite de maior renda, composta pelos grandes empregadores locais, por dirigentes do setor público e privado e por profissionais autônomos ou empregados de nível superior; setores médios e pequenos empregadores com um peso mais reduzido em relação a outras metrópoles brasileiras; e um contingente expressivo de trabalhadores em atividades terciárias, e um proletariado secundário, no qual a participação da indústria de transformação era especialmente restrita (CARVALHO; PEREIRA, 2008). No começo dos anos 2000 continuava a persistir em Salva- 
dor altas taxas de desemprego e, sobretudo, altas taxas de subemprego, taxa esta que se encontrava entre as maiores das regiões metropolitanas do Brasil (CASTRO; BARRETO, 1998).

\section{METODOLOGIA}

\subsection{Caracterização da pesquisa}

Para elaboração do presente artigo foi necessário realizar um resgate teórico do tema em questão por meio de uma revisão de literatura, além de realizar também uma abordagem empírica através de informações presente no banco de dados da Pesquisa do Emprego e Desemprego (PED) para os anos 2003-2010. A utilização de gráficos e tabelas ajuda a compreender as possíveis mudanças ocorridas nas questões de ordem sócio-ocupacional na Região Metropolitana de Salvador.

\subsection{Base de dados}

A base de dados que apresentam as informações concernentes ao estudo em questão foram obtidas da Pesquisa de Emprego e Desemprego (PED). A PED tem como unidade amostral o domicílio da área urbana que a compõem. A metodologia de sorteio produz uma amostra equiproporcional em dois estágios, sendo os setores censitários sorteados dentro de cada Zona de interpolação e os domicílios dentro de cada SC. Estes municípios estão subdivididos em 17 distritos, 22 subdistritos, 165 zonas de informação (ZI) e 2.243 setores censitários (SC). A Pesquisa coleta informações mensalmente, através de entrevistas com moradores de 10 anos de idade ou mais, em 2.500 domicílios da Região Me- tropolitana de Salvador, resultando na aplicação de cerca de 9.000 questionários/mês (DIEESE, 2012).

\subsection{Os anos 2003 a 2010}

O interregno 2003 a 2010 foi escolhido por ser considerado um período de importantes mudanças sociais e econômicas ocorridas no país. $O$ ano de 2003, por exemplo, assinala o início de um processo de adoção deliberada de um conjunto de políticas econômicas expansivas em detrimento daquelas de cunho ortodoxo, estas que até então eram o "carro-chefe" das políticas econômicas adotadas. Já o ano de 2010 é o primeiro ano posterior a crise econômica internacional, esta que foi provocada pela deblachê do Leman Brothers, com efeitos negativos sobre a economia mundial.

\section{MUDANÇAS OCORRIDAS NA RMS}

\subsection{Situação ocupacional na RMS}

Até pelo menos o ano de 2003, a marca mais expressiva da configuração do mercado de trabalho na RMS foi a persistência de altas taxas de desemprego, aliadas a um expressivo contingente de trabalhadores inseridos precariamente no mundo do trabalho. A partir de 2004, os dados da PED passaram a registrar um importante crescimento da taxa de ocupação na RMS e consequente queda da taxa de desocupação, tanto na categoria desemprego aberto, precário e desalento. Observa-se ainda que no ano de 2010 em relação a 2003, a taxa de ocupação cresceu $4,6 \%$ e a taxa de desemprego aberto teve uma queda de $3,4 \%$. Verifica-se também que em 2009, a taxa de ocupações teve uma ligeira queda, mas vol- 
tou a crescer em 2010 com percentual mais significativo quando comparado a qualquer outro período da série em análise.

Ademais, vale destacar que o direcionamento dado a economia para promoção do crescimento econômico através de políticas econômicas expansivas corroborou para impulsionar o aumento das ocupações no mercado de trabalho, como pode ser visto na Tabela 1:

Tabela 1 - Situação ocupacional na RMS

Table 1 - Occupational situation in RMS

\begin{tabular}{|l|c|c|c|c|c|c|c|}
\hline & $\begin{array}{c}\text { Des. } \\
\text { com tr. } \\
\text { precário }\end{array}$ & $\begin{array}{c}\text { Des. } \\
\text { Aberto }\end{array}$ & $\begin{array}{c}\text { Des. } \\
\text { dasa- } \\
\text { lento }\end{array}$ & $\begin{array}{c}\text { Ocu- } \\
\text { pado }\end{array}$ & $\begin{array}{c}\text { Inativo } \\
\text { com } \\
\text { trab. } \\
\text { excep. }\end{array}$ & $\begin{array}{c}\text { Inativo } \\
\text { puro }\end{array}$ & $\begin{array}{c}\text { Menores } \\
\text { de } 10 \\
\text { anos }\end{array}$ \\
\hline 2003 & $4,0 \%$ & $9,0 \%$ & $1,8 \%$ & $38,0 \%$ & $0,9 \%$ & $30,4 \%$ & $15,9 \%$ \\
\hline 2004 & $4,0 \%$ & $7,8 \%$ & $1,6 \%$ & $39,0 \%$ & $1,0 \%$ & $31,3 \%$ & $15,3 \%$ \\
\hline 2005 & $3,8 \%$ & $7,4 \%$ & $1,4 \%$ & $39,2 \%$ & $0,9 \%$ & $32,1 \%$ & $15,2 \%$ \\
\hline 2006 & $3,4 \%$ & $7,8 \%$ & $1,1 \%$ & $39,7 \%$ & $0,6 \%$ & $33,1 \%$ & $14,4 \%$ \\
\hline 2007 & $3,3 \%$ & $7,3 \%$ & $0,9 \%$ & $41,3 \%$ & $0,5 \%$ & $32,9 \%$ & $13,9 \%$ \\
\hline 2008 & $3,0 \%$ & $6,3 \%$ & $1,2 \%$ & $41,3 \%$ & $0,8 \%$ & $33,7 \%$ & $13,6 \%$ \\
\hline 2009 & $2,6 \%$ & $6,2 \%$ & $1,1 \%$ & $41,1 \%$ & $0,4 \%$ & $35,8 \%$ & $12,8 \%$ \\
\hline 2010 & $2,0 \%$ & $5,6 \%$ & $0,9 \%$ & $42,6 \%$ & $0,5 \%$ & $36,1 \%$ & $12,3 \%$ \\
\hline
\end{tabular}

Fonte - Elaboração própria, 2016, com base nos dados PED. Software spss 22

O crescimento econômico vivenciado pelo país contribuiu para o processo de formalização dos contratos de trabalho na RMS e geração de empregos formais. Assim, na RMS, de 2004 a 2010, a taxa de pessoas ocupadas com carteira assinada apresentou um crescimento significativo (da ordem de $10,2 \%)$ como pode ser observado no Gráfico 1:
Gráfico 1 - Pessoas que trabalham com carteira assinada Graph 1 - People who work with a formal contract

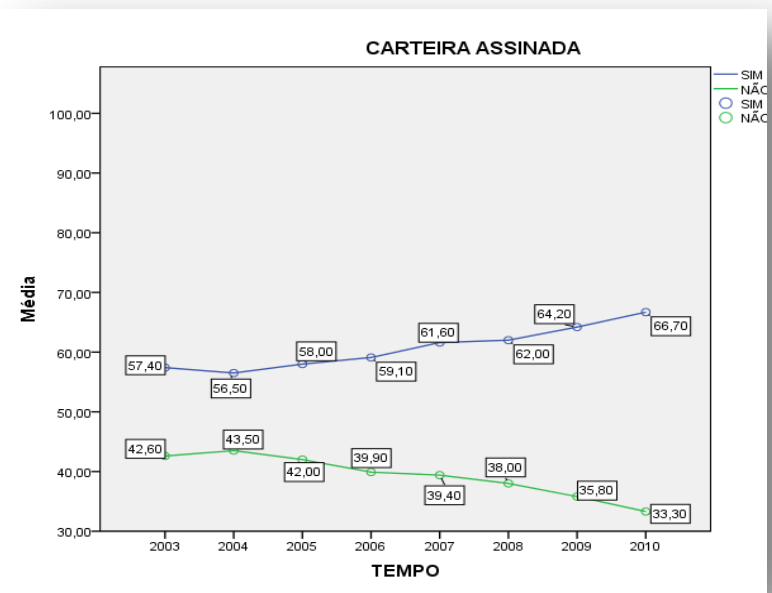

Fonte - Elaboração própria, 2016, com base nos dados da PED. Software spss 22

\subsection{Setor de atividade}

Analisando os setores de atividades (Gráfico 2), observa-se que na indústria de transformação além de haver baixo contingente de trabalhadores ocupados em relação a outros setores, este setor apresentou de 2003 a 2010 um declínio do quantum de ocupações. Assim, o tamanho da força de trabalho da indústria de transformação na ocupação total da RMS permaneceu pequeno (8,2\% em 2010), sendo maior apenas que o setor da construção civil.

Falando ainda sobre setores de atividade, observa-se que maior parte da força de trabalho da RMS está ocupada no setor de serviços. A taxa de pessoas ocupadas no referido setor apresentou um comportamento cíclico ao longo dessas anos, mas ao fim do período em analise (ano de 2010) apresentou um crescimento relativamente modesto em relação ao início (em relação a 2003). Vale salientar que o setor de serviços na RMS é caracterizado por atividades bastante heterogêneas quanto ao porte da 
empresa, à remuneração média e a intensidade no uso de tecnologias. São atividades diversas em empreendimentos, tais como: salão de beleza, bares, restaurantes, lanchonetes, consertos, manutenção e assistência técnica, telemarketing, T.I dentre outros, atividades que, geralmente, são de baixo nível agregação e de sofisticação técnica. Quanto ao crescimento ocupacional no ramo do comércio, setor em que aparece em segundo lugar no ranking de pessoas ocupadas, este por sua vez apresentou constante oscilação ao longo de todo período, registrando um crescimento pequeno em 2010 comparado a 2003. Diante do exposto, verifica-se que a maioria das ocupações está vinculada ao setor de serviços e ao comércio, setores que nessa região, em geral, não se destacam pela geração de empregos que exige maior qualificação técnica da força de trabalho.

O setor de atividade que apresentou maior taxa de crescimento em termos de ocupações entre 2003 e 2010 na RMS foi o setor da construção civil $^{5}$. Nesse processo os investimentos produtivos que foram implementados contribuíram para mobilizar fatores de produção que outrora estavam ociosos na referida região. Pode-se ainda observar que em 2009, ano em que os efeitos da crise internacional se fizeram sentir no Brasil, a taxa de ocupação no setor da construção civil continuou apresentando um importante crescimento. Pode-se inferir que tal fato é decorrente da adoção de medidas econômicas contracíclicas ${ }^{6}$ adotadas

\footnotetext{
${ }^{5}$ Como tem apontado outros estudos, o crescimento na taxa de ocupações ocorrido no setor da construção civil esteve associado ao ciclo virtuoso vivenciado pela economia brasileira a partir de 2003

${ }^{6}$ Políticas que visam minimizar os efeitos das crises e flutuações econômicos. Podem ser políticas fiscais, tais
}

com objetivo de arrefecer os efeitos da crise internacional.

Gráfico 2 - setores de atividade

Graph 3 - sectors of activity

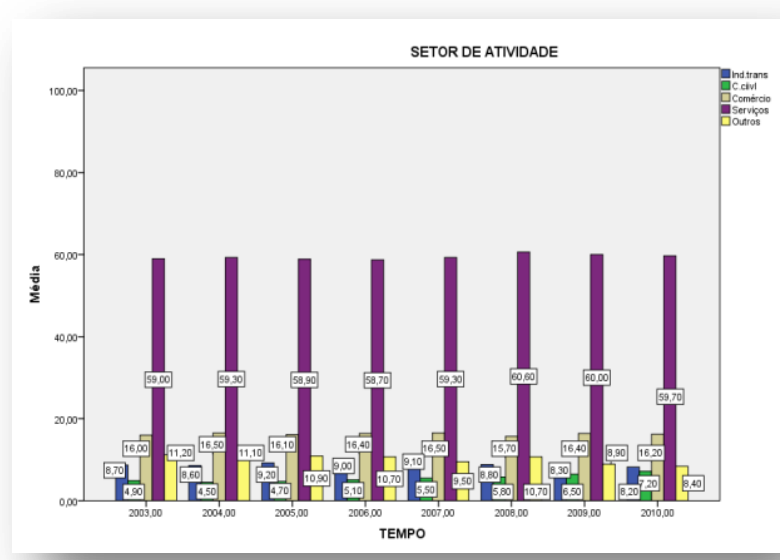

\subsubsection{Posição na ocupação}

No que tange a categoria "posição na ocupação" a única que apresentou crescimento nesse período na RMS foi a categoria "empregados", enquanto as demais categorias registrou queda, com destaque para a dos "autônomos". Esse fato nos permite inferir que o processo de crescimento econômico vivenciado pelo Brasil e, consequentemente, pela RMS contribuiu para aumentar o número de empregos formais, a despeito do percentual de pessoas na condição de autônomos ainda continuar elevada. Dito isso, verifica-se que há um elevado contingente de pessoas que ainda continuam exercendo atividades laborais informais e muitas delas em condições precárias.

Ademais, a taxa de pessoas na condição de empregador não apresentou evolução significativa ao longo desse processo e o

como aumento do gasto público e diminuição dos tributos, e podem ser também políticas monetárias (diminuição das taxas de juros, por exemplo). A diminuição das taxas de juros incentiva o aumento da produção por parte do empresariado. 
número de pessoas atuando na condição de "trabalhador liberal", na média, também não apresentou crescimento.

Tabela 2 - Posição na ocupação

Table 2 - Position in the occupation

\begin{tabular}{|c|c|c|c|c|c|}
\hline & $\begin{array}{c}\text { Emprega- } \\
\text { do }\end{array}$ & Autônomo & $\begin{array}{c}\text { Emprega- } \\
\text { dor }\end{array}$ & $\begin{array}{c}\text { Prof. Libe- } \\
\text { ral }\end{array}$ & Outros \\
\hline 2003 & $72,30 \%$ & $21,60 \%$ & $3,80 \%$ & $0,60 \%$ & $1,60 \%$ \\
\hline 2004 & $71,40 \%$ & $22,00 \%$ & $4,10 \%$ & $0,80 \%$ & $1,80 \%$ \\
\hline 2005 & $72,60 \%$ & $21,50 \%$ & $3,90 \%$ & $0,60 \%$ & $1,40 \%$ \\
\hline 2006 & $73,10 \%$ & $21,00 \%$ & $3,80 \%$ & $0,70 \%$ & $1,40 \%$ \\
\hline 2007 & $74,00 \%$ & $20,10 \%$ & $3,50 \%$ & $0,70 \%$ & $1,70 \%$ \\
\hline 2008 & $73,40 \%$ & $21,10 \%$ & $3,30 \%$ & $0,50 \%$ & $1,80 \%$ \\
\hline 2009 & $74,00 \%$ & $21,30 \%$ & $2,70 \%$ & $0,40 \%$ & $1,20 \%$ \\
\hline 2010 & $75,10 \%$ & $19,70 \%$ & $3,10 \%$ & $0,50 \%$ & $1,60 \%$ \\
\hline
\end{tabular}

Fonte - Elaboração própria, 2016, com base nos dados da PED

\subsubsection{Tipo de empregado}

Os dados da PED relacionado ao tipo de emprego na RMS também nos mostram um fato importante: o número de trabalhadores assalariados, ou seja, que recebem rendimentos fixos com prazo legal de reajuste cresceu na referida região no período em questão, com destaque para os "assalariados com comissão". A taxa em percentual de trabalhadores na categoria "ganha em espécie" e na categoria "militar religioso" (capelão) permaneceu praticamente estática ao longo desses anos. Já a categoria de "trabalhadores que ganha por produção" apresentou diminuição de 1,2\%. Mas vale destacar a importante evolução ocorrida no universo do trabalho doméstico, este que registrou uma queda de 4,4\%, (Tabela 3):
Tabela 3 - tipo de empregado

Table 3 - type of employee

\begin{tabular}{|c|c|c|c|c|c|c|c|}
\hline & $\begin{array}{c}\text { Ass. } \\
\text { com } \\
\text { comis- } \\
\text { são }\end{array}$ & $\begin{array}{c}\text { Ass. } \\
\text { sem } \\
\text { comis- } \\
\text { são }\end{array}$ & $\begin{array}{c}\text { Ganha } \\
\text { em } \\
\text { espécie }\end{array}$ & Mil, Rel & $\begin{array}{c}\text { Por } \\
\text { produ- } \\
\text { ção }\end{array}$ & $\begin{array}{c}\text { Dom. } \\
\text { mes }\end{array}$ & $\begin{array}{c}\text { Ou- } \\
\text { tros }\end{array}$ \\
\hline 2003 & $81,5 \%$ & $2,4 \%$ & $0,1 \%$ & $0,1 \%$ & $2,0 \%$ & $12,1 \%$ & $1,9 \%$ \\
\hline 2004 & $81,9 \%$ & $2,0 \%$ & $0,1 \%$ & $0,1 \%$ & $2,2 \%$ & $12,0 \%$ & $1,6 \%$ \\
\hline 2005 & $82,9 \%$ & $2,2 \%$ & $0,0 \%$ & $0,1 \%$ & $1,7 \%$ & $11,4 \%$ & $1,5 \%$ \\
\hline 2006 & $83,5 \%$ & $2,5 \%$ & $0,0 \%$ & $0,2 \%$ & $1,1 \%$ & $11,1 \%$ & $1,6 \%$ \\
\hline 2007 & $83,8 \%$ & $2,8 \%$ & $0,1 \%$ & $0,1 \%$ & $1,4 \%$ & $10,1 \%$ & $1,6 \%$ \\
\hline 2008 & $83,7 \%$ & $3,4 \%$ & $0,1 \%$ & $0,2 \%$ & $1,4 \%$ & $9,4 \%$ & $1,8 \%$ \\
\hline 2009 & $85,6 \%$ & $3,0 \%$ & $0,1 \%$ & $0,1 \%$ & $0,8 \%$ & $8,4 \%$ & $2,1 \%$ \\
\hline 2010 & $86,3 \%$ & $3,0 \%$ & $0,1 \%$ & $0,1 \%$ & $0,8 \%$ & $7,7 \%$ & $2,0 \%$ \\
\hline
\end{tabular}

Fonte - Elaboração própria, 2016, com base nos dados da PED

A mudança na situação do trabalhador doméstico verificada nesse período também está relacionada elevação ocorrida no nível educacional ocorrido entre esses trabalhadores, como pode ser visto no quadro 4. O número de "trabalhadores domésticos" com apenas o primeiro grau completo apenas, juntamente com aqueles que "nunca frequentou a escola", apresentou uma diminuição considerável de 2003 a 2010, enquanto o percentual daqueles que possuem segundo grau completo aumentou significativamente, conforme a Tabela 4 a seguir

Tabela 4 - Escolaridade dos que trabalham como empregados domésticos

Table 4 - Schooling of those who work as domestic servants

\begin{tabular}{|c|c|c|c|c|}
\hline & $1^{\circ}$ & $2^{\circ}$ & $3^{\circ}$ & Nunca frequentou \\
\hline 2003 & $68,9 \%$ & $22,5 \%$ & $0,1 \%$ & $8,5 \%$ \\
\hline 2004 & $68,3 \%$ & $24,1 \%$ & $0,1 \%$ & $7,5 \%$ \\
\hline 2005 & $67,0 \%$ & $26,7 \%$ & $0,1 \%$ & $6,2 \%$ \\
\hline 2006 & $62,9 \%$ & $30,2 \%$ & $0,3 \%$ & $6,6 \%$ \\
\hline 2007 & $64,6 \%$ & $29,4 \%$ & $0,2 \%$ & $5,7 \%$ \\
\hline 2008 & $61,4 \%$ & $33,3 \%$ & $0,3 \%$ & $5,0 \%$ \\
\hline 2009 & $38,9 \%$ & $35,6 \%$ & $0,5 \%$ & $4,9 \%$ \\
\hline 2010 & $58,7 \%$ & $37,7 \%$ & $0,4 \%$ & $3,2 \%$ \\
\hline
\end{tabular}

Fonte - Elaboração própria, 2016, com base nos dados da PED

Observa-se ainda que a taxa de trabalhadores na condição de "domésticos com terceiro grau completo" apresentou evolução ao longo desses anos, embora tenha sido modesta. Além disso, deve-se observar também que a taxa de pessoas que "nunca 
frequentaram a escola" apresentou uma significativa diminuição, reduzindo-se de $8,5 \%$ para $3,2 \%^{7}$ entre 2003 e 2010.

Nesse processo, a taxa de "inativos" apresentou um comportamento bastante irregular, bem como a categoria "encostados na caixa". As categoriais "estudantes" e "vive de ajuda" diminuíram em percentual e a categoria "encostado na caixa" apresentou um comportamento bastante cíclico nesse processo. Já a nomenclatura "inativos que vivem de renda" manteve seu percentual constante e a categoria dos que "vivem de ajuda" também apresentou diminuição.

Tabela 5 - Tipo de inatividade

Table 5 - Type of inactivity

\begin{tabular}{|c|c|c|c|c|c|c|}
\hline & $\begin{array}{c}\text { Enc. na } \\
\text { caixa }\end{array}$ & $\begin{array}{c}\text { A. do- } \\
\text { mésticos }\end{array}$ & $\begin{array}{c}\text { Estudan- } \\
\text { te }\end{array}$ & $\begin{array}{c}\text { Vive de } \\
\text { renda }\end{array}$ & $\begin{array}{c}\text { Vive de } \\
\text { ajuda }\end{array}$ & Outra \\
\hline 2003 & $1,5 \%$ & $19,9 \%$ & $43,3 \%$ & $0,7 \%$ & $10,1 \%$ & $0,7 \%$ \\
\hline 2004 & $2,0 \%$ & $19,6 \%$ & $42,7 \%$ & $0,7 \%$ & $10,2 \%$ & $0,7 \%$ \\
\hline 2005 & $2,7 \%$ & $19,9 \%$ & $42,0 \%$ & $0,6 \%$ & $10,8 \%$ & $0,7 \%$ \\
\hline 2006 & $2,3 \%$ & $19,6 \%$ & $40,5 \%$ & $0,7 \%$ & $11,2 \%$ & $0,7 \%$ \\
\hline 2007 & $2,6 \%$ & $19,0 \%$ & $31,9 \%$ & $0,8 \%$ & $10,5 \%$ & $1,1 \%$ \\
\hline 2008 & $2,4 \%$ & $20,4 \%$ & $39,1 \%$ & $0,8 \%$ & $8,2 \%$ & $1,3 \%$ \\
\hline 2009 & $2,2 \%$ & $19,6 \%$ & $39,9 \%$ & $0,7 \%$ & $8,8 \%$ & $1,1 \%$ \\
\hline 2010 & $1,6 \%$ & $20,9 \%$ & $38,1 \%$ & $0,6 \%$ & $8,7 \%$ & $1,1 \%$ \\
\hline
\end{tabular}

Fonte - Elaboração própria, 2016, com base nos dados da PED

Mas, a categoria "aposentados" registrou evolução bastante significativa no período em questão em relação as demais, como pode ser visto no Gráfico 3:

${ }^{7}$ Embora tenha sido registrado um importante processo de formalização no mercado de trabalho, os serviços domésticos mantêm a posição de atividade com grau mais elevado de "desproteção", pois os dados da PED apontam que $64,1 \%$ dos trabalhadores domésticos não eram formalizados no ano de 2010.
Gráfico 3 - Gráfico dos aposentados na RMS Graph 3 - Type of inactivity

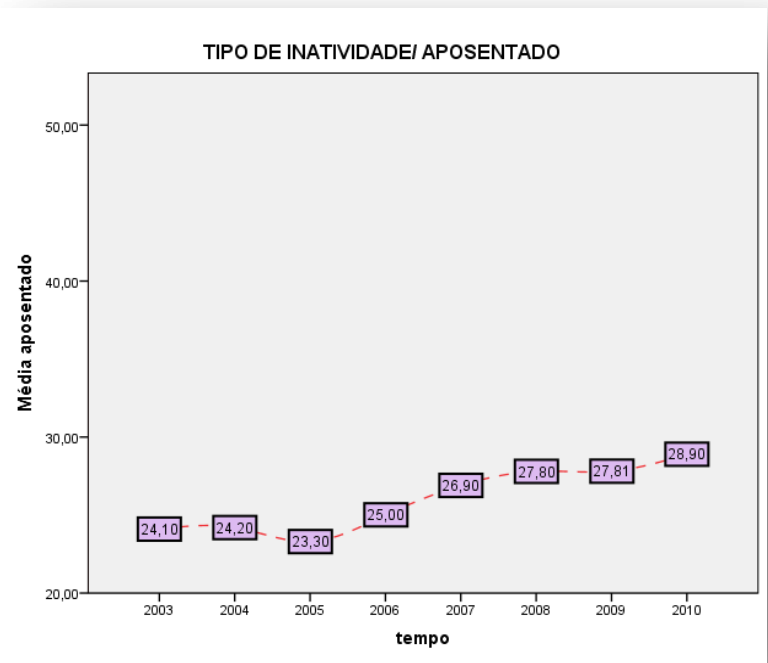

Fonte - Elaboração própria, 2016, com base nos dados da PED. Software spss 22

4.2.3 Faixa de renda em Salvador por famílias

Vale destacar que embora tenha ocorrido uma importante evolução nos aspectos sócio-ocupacionais na Região Metropolitana de Salvador observa-se que ainda há na referida região um número expressivo de famílias que aufere renda familiar inferior a um salário mínimo, ou seja, que vive com renda insuficiente para atender parte significativa das necessidades humanas mais básicas.

Tabela 6 - Família que vive com renda entre $1 / 2$ e 1 salário mínimo

Table 6 - Family living with income between $1 / 2$ and 1 minimum wage

\begin{tabular}{|c|c|}
\hline Ano & De 1/2 salário a 1 mínimo \\
\hline 2003 & $29,9 \%$ \\
\hline 2004 & $30,4 \%$ \\
\hline 2005 & $29,0 \%$ \\
\hline 2006 & $28,7 \%$ \\
\hline 2007 & $28,8 \%$ \\
\hline 2008 & $26,1 \%$ \\
\hline 2009 & $29,6 \%$ \\
\hline 2010 & $26,9 \%$ \\
\hline
\end{tabular}

Fonte - Elaboração própria, 2016, com base nos dados da PED 
Os dados também nos mostram que é considerável o número de famílias que vivem na Grande Salvador com renda que varia de 1 a 4 salários mínimos.

Tabela 7 - Família que vive com renda entre 1 a 2 S.M e 2 a 4 S.M

Table 7 - Family living with income between 1 to 2 S.M and 2 to 4 S.M

\begin{tabular}{|c|c|c|}
\hline Ano & 1 a 2 salários mínimos & De 2 a 4 salários mínimos \\
\hline 2003 & $16,5 \%$ & $20,1 \%$ \\
\hline 2004 & $16,1 \%$ & $19,9 \%$ \\
\hline 2005 & $17,4 \%$ & $19,1 \%$ \\
\hline 2006 & $18,7 \%$ & $20,4 \%$ \\
\hline 2007 & $17,9 \%$ & $21,6 \%$ \\
\hline 2008 & $17,7 \%$ & $22,0 \%$ \\
\hline 2009 & $18,0 \%$ & $20,3 \%$ \\
\hline 2010 & $20,1 \%$ & $21,3 \%$ \\
\hline
\end{tabular}

Assim, conforme os critérios de estratificação social do IBGE, que divide as classes econômicas conforme a renda auferida pelas famílias, observa-se que quase $80 \%$ da população da RMS está situadas nas classes $D$ e $E^{8}$. Verifica-se ainda que o número de famílias situadas na classe $C$, isto é, que aufere renda entre 4 a 10 salários mínimos continuou estável ao longo dos anos em questão, conforme a Tabela 8. Ainda de acordo os dados da referida Tabela 8 , verifica-se que o percentual de famílias situadas na classe $B$, ou seja, que aufere renda mensal entre 10 a 20 salários, encolheu no período em questão.

\footnotetext{
${ }^{8}$ De acordo com o IBGE pertencem a classe E aquelas famílias que aufere renda mensal entre 0 a 2 salários mínimos e a classe $D$ àquelas que recebem mensalmente renda equivalente entre de 2 a 4 salários mínimos
}

Tabela 8 - Famílias que vivem com renda entre 4 a 10 S.M e de 10 a 20 S.M

Table 8 - Families living with income between 4 to 10 S.M and 10 to 20 S.M

\begin{tabular}{|c|c|c|}
\hline Ano & 4 a 10 salários mínimos & De 10 a 20 salários mínimos \\
\hline 2003 & $16,6 \%$ & $5,8 \%$ \\
\hline 2004 & $16,1 \%$ & $5,9 \%$ \\
\hline 2005 & $16,1 \%$ & $5,5 \%$ \\
\hline 2006 & $15,1 \%$ & $4,7 \%$ \\
\hline 2007 & $16,5 \%$ & $5,0 \%$ \\
\hline 2008 & $17,9 \%$ & $5,7 \%$ \\
\hline 2009 & $16,1 \%$ & $4,9 \%$ \\
\hline 2010 & $16,3 \%$ & $4,3 \%$ \\
\hline
\end{tabular}

O mesmo processo de retração ocorreu com a classe $A$, ou seja, com o estrato de renda onde estão situadas as famílias mais ricas. Ademais, os dados da Tabela 9 nos mostram que parcela diminuta da população da RMS aufere renda mensal superior a 20 salários mínimos, fato que evidência que a referida é região ainda continua bastante desigual e com elevada concentração de renda.

Tabela 9 - Famílias que vivem com renda acima de 20 S.M

Table 9 - Families living with income above 20 S.M

\begin{tabular}{|c|c|}
\hline Ano & Acima de 20 salários mínimos \\
\hline 2003 & $2,7 \%$ \\
\hline 2004 & $2,6 \%$ \\
\hline 2005 & $2,4 \%$ \\
\hline 2006 & $1,7 \%$ \\
\hline 2007 & $1,3 \%$ \\
\hline 2008 & $1,9 \%$ \\
\hline 2009 & $1,2 \%$ \\
\hline 2010 & $1,2 \%$ \\
\hline
\end{tabular}

\section{CONCLUSÃO}

Como foi observado, entre 2003 e 2010 ocorreu na Região Metropolitana de Salvador uma evolução importante em muitos aspectos sócio-ocupacionais. Tal evolução decorreu do processo de melhoria da distribuição de renda que esteve em curso no país, fruto das políticas sociais que passaram a ser adotadas. Nesse processo, a taxa de ocupados cresceu significativamente na 
RMS, e a de desemprego apresentou importante queda; o número de pessoas que passaram a contribuir com a previdência social também evoluiu positivamente e a taxa de aposentados apresentou considerável crescimento. Este fato, inclusive, evidencia que a malha de proteção social se estendeu a um contingente importante de pessoas na referida região.

Mas os setores que apresentaram crescimento em termos de criação de oportunidades de trabalho foram setores menos dinâmicos e de baixa qualificação técnica, a exemplo do setor de serviços, comércio e construção civil, e não em atividades econômicas que agregam mais valor ao produto e que requerem, inclusive, maior grau de qualificação da força de trabalho e sofisticação técnica, como é o caso da indústria de transformação.

A despeito do importante processo de evolução ocorrido nas questões sociais e ocupacionais na RMS, deve-se ressaltar que na região supracitada há questões sociais graves que ainda persiste, sendo a mais grave delas a concentração de renda, visto que a maior parte das famílias na referida região sobrevive com até 1 salário mínimo, enquanto pouco mais de $1 \%$ aufere renda mensal acima de 20 salários mínimos. Desse modo, pode-se inferir que não ocorreu na Grande Salvador no período em questão mudanças que possam configurar um processo radical de transformação do seu panorama social.

\section{REFERÊNCIAS}

BACELAR, J. O negro em Salvador: os ataIhos raciais. R. História, São Paulo, n. 129131, p. 53-05, ago.-dez. 1994.

CASTRO, N. A; BARRETO, V. S. Trabalho e desigualdades raciais negros e brancos no mercado de trabalho em Salvador. São Paulo, Anablume, 1998.

CARVALHO, I. M. M; ÂNGELA, G. de S; PEREIRA, G. C. Polarização e segregação Socioespacial em uma metrópole periférica. CADERNO CRH, Salvador, v.17, n. 41, p. 281-297, Mai./Ago. 2004.

CARVALHO, I. M. M; BARRETO, V. S. Segregação residencial, condição social e raça em Salvador. Cadernos Metrópole pp. 251-273, $2^{\circ}$ sem. 2007.

CARVALHO, I. M. M.; PEREIRA, G. C. Como anda Salvador e sua Região Metropolitana? 2. ed. Salvador: UFBA, 2008.

CARVALHO, I. M. M.; PEREIRA, G. C.; FERNANDES, C. M. Desigualdade e bem estar urbano na região Metropolitana de Salvador. Disponível em: <http://www.observato riodasmetropoles.net/download/ibeu_salva dor.pdf>. Acesso em: 05/nov.2015.

CARVALHO, I. M. M; SOUZA, G. A. A. Produção não capitalista no desenvolvimento do capitalismo em Salvador. In: FARIA, Vilmar Souza (Org.). Bahia de todos os pobres. Petrópolis: Vozes, 1980. p. 71-102.

DIEESE. A situação do trabalho no Brasil na primeira década dos anos 2000. São Paulo, 2012.

GUIMARÃES, A. S. A. Estrutura e formação das classes sociais em Salvador. Disponível em: <www.cadernocrh.ufba.br/include/get doc.php?id=1539\& article...> Acesso em: 12/ mai./ 2015.

OLIVEIRA, F. 0 elo perdido classe e identidade de classes na Bahia. São Paulo: Fundação Perseu Abramo, 2003.

SANTOS, V. M. dos. O significado do Sistema 34/18-FINOR no processo recente de industrialização do Nordeste. Cadernos de Estudos Sociais: Recife, v. 11, n. 1, p. 117140, jan./jun.1994. 

access article distributed under the terms of the Creative Commons Attribution License, which permits unrestricted use, distribution, and reproduction in any medium, provided the original work is properly cited.

Artigo recebido em 17 de junho de 2016.

Avaliado em 04 de agosto de 2017.

Aceito em 18 de setembro de 2017.

Publicado em 22 de setembro de 2017.

\section{Como citar este artigo (ABNT):}

OLIVEIRA, Ualace Roberto de Jesus. O que mudou na grande Salvador? Um breve estudo sobre a evolução dos aspectos sócioocupacionais na Região Metropolitana de Salvador entre 2003 e 2010. Estação Científica (UNIFAP), Macapá, v. 7, n. 2, p. 115128, maio/ago. 2017. 